\title{
Alcohol consumption and sports-betting among young male motorcycle taxi boda boda riders in urban southwestern Uganda
}

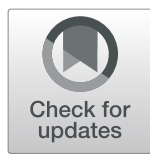

Stella Cheryl Nabifo, Jonathan Izudi and Francis Bajunirwe* (D)

\begin{abstract}
Background: The popularity of sports-betting is growing globally and may be associated with alcohol consumption among young adults. In this study, we examine the relationship between alcohol consumption plus other substances with sports-betting in a group of young adult males in Uganda.

Methods: We conducted a cross-sectional study and interviewed male motorcycle taxi boda boda riders in the southwestern Uganda town of Mbarara. We asked questions about alcohol consumption, smoking plus history and frequency of sports-betting.

Results: We enrolled 401 riders. The median age was 29.0 years, interquartile range 25-32 years. Seventy four (18.5\%) had engaged in sports-betting in the past 30 days. Among those that reported sports-betting, 16(21.6\%) engaged daily or almost daily. Alcohol use was significantly associated with sports-betting with an adjusted risk ratio (aRR) of 2.08(95\% $\mathrm{Cl} 1.36,3.18)$ among moderate drinkers but not among heavy drinkers in comparison to low or non-drinkers. Cigarette smoking was significantly associated with sports-betting with an aRR $1.85(95 \% \mathrm{Cl} 1.13,3.01)$.

Conclusion: Sports-betting is common among these young male motorcycle riders, and is associated with both alcohol consumption and cigarette smoking. Interventions to regulate sports-betting may be co-packaged with those to reduce alcohol consumption and cigarette smoking among young adult males.
\end{abstract}

Keywords: Sports-betting, Alcohol consumption, Uganda, Young males

\section{Background}

There is a global increase in the popularity of sportsbetting and this is likely due to the involvement of sportsbetting companies in sponsorship and advertisement in popular sports events such as soccer [1]. The number of sports-betting companies involved in shirt sponsorship for football in European leagues has grown exponentially. In the top five European soccer leagues namely England, Germany, Italy, France, and Portugal, shirt sponsorship grew from one deal in the $2002 / 3$ season to 26 in the 2010/11 season [2]. In the widely popular English Premier

\footnotetext{
* Correspondence: fbaj@yahoo.com

Department of Community Health, Mbarara University of Science and Technology, P.O.BOX 1410 Mbarara, Uganda
}

League alone, gambling companies that have first team shirt sponsorships grew from four deals in 2008, to six in 2012, and ten in 2017, accounting for half of the 20 English Premier League teams [3].

Soccer is the most popular game in majority of countries in sub Saharan Africa. The European soccer leagues are extremely popular in Africa and therefore soccer sponsors such as sports betting companies are likely to reach a very wide audience on the continent through their advertisement. Sports betting in Uganda is legal and one of the rapidly expanding industries now with presence of international betting companies throughout the country [4]. The betting industry has grown over the years that by June 2015, there were at least 23 licensed

(c) The Author(s). 2021 Open Access This article is licensed under a Creative Commons Attribution 4.0 International License, which permits use, sharing, adaptation, distribution and reproduction in any medium or format, as long as you give appropriate credit to the original author(s) and the source, provide a link to the Creative Commons licence, and indicate if changes were made. The images or other third party material in this article are included in the article's Creative Commons licence, unless indicated otherwise in a credit line to the material. If material is not included in the article's Creative Commons licence and your intended use is not permitted by statutory regulation or exceeds the permitted use, you will need to obtain permission directly from the copyright holder. To view a copy of this licence, visit http://creativecommons.org/licenses/by/4.0/ The Creative Commons Public Domain Dedication waiver (http://creativecommons.org/publicdomain/zero/1.0/) applies to the data made available in this article, unless otherwise stated in a credit line to the data. 
betting companies that were operational, with at least 1000 betting outlets in the country [5]. The companies have made betting even more accessible through the provision of online services that customers can access through their mobile phones and telephone service providers [6]. The sports betting industry is well-regulated and government has instituted regulations that only individuals who have reached the legal age of $\geq 18$ years are permitted to participate [6].

Existing data suggest that males are more knowledgeable and engage more in sports betting and those that have peers who gamble tend to generally have positive attitudes towards sports betting [7]. In Uganda, a previous study reports that younger people are more likely to engage in sports betting and do this both for fun and to win money [8]. The same young crowd of males is also drawn to soccer matches where they are ardent supporters of the mostly foreign soccer leagues in Europe. The linkage between soccer and sportsbetting or gambling advertisement exposes the football fans to the allure of sports-betting and poses potential public health threats to the soccer fans, majority of who are minors or young adults, because of the potential risk of developing problem gambling [9-11] and addiction. Gambling also increases the risk for financial problems, mental health conditions such as anxiety, depression, suicide, and problematic relationships at the family level particularly with spouse, children, and parents [12]..

The global marketing of sports-betting and alcoholic products together in live sports events such as soccer matches is very common [13] and betting advertisement associates significant moments of sports such as scoring goals with alcohol [14]. Alcohol consumption has been linked to gambling including sports-betting. Several studies have confirmed the association between alcohol consumption and sports-betting $[15,16]$ and also with smoking or substance abuse [17]. However, most of these studies have been conducted in resource rich settings.

In resource limited settings like Uganda, because of the popularity of soccer, exposure to sports-betting advertisement is increasing and anecdotal reports suggest that sports-betting may also be on the rise especially among youth in urban and peri-urban areas. Motorcycle taxis commonly referred to as bodabodas are operated by a predominantly youthful urban male population, who earn a daily income and may be a soft target for the sports-betting industry. There is limited empiric data on the frequency of gambling in the populations that have been targeted by the sports-betting companies.

Therefore, the purpose of this study was to establish the frequency and pattern of sports-betting, and the relationship between alcohol consumption and sportsbetting among boda boda riders in an urban setting in Uganda. We hypothesized that alcohol consumption and cigarette smoking are associated with increased likelihood of sports-betting. Smoking and heavy alcohol consumption in early adulthood have long-term negative impact on health, earnings and employment later in life especially among males [18]. The data from this study will provide evidence to support measures or policies to regulate sports betting in resource limited settings where the practice is on the increase and also potentially support the integration of alcohol and sports-betting regulation.

\section{Methods \\ Setting}

We conducted a cross sectional study in Mbarara municipality located in Mbarara district in south-western Uganda. The municipality is a mixed urban and periurban setting with an estimated population of nearly 100,000 inhabitants. Located $250 \mathrm{~km}$ from the capital Kampala, it is the largest urban setting in southwestern Uganda.

\section{Study participants and sampling}

The boda boda cyclists are predominantly male, with a very small number of female riders [19]. The riders are identifiable by the stage where they operate from. A stage is an area where a group of riders congregate and wait for passengers and the stages are scattered across the municipality. Each boda boda stage has a different number of riders ranging from a few to almost 15 in the more crowded areas of the municipality.

We used a multi stage sampling approach to select the stages from which our respondents were enrolled. In this multi-stage approach, we started at the division (or subcounty), the largest geographical unit in the municipality. We purposively selected divisions that had the largest number of boda boda cyclists. We then listed all the stages in the selected divisions using unique codes in an Excel sheet and then performed simple random sampling to select the boda boda stages. At the selected stages, we conducted a census of all boda boda cyclists and randomly selected from the list. We selected an equal number of cyclists from each stage. Our sample size calculation was adjusted for the design effect arising from potential clustering of riders at a given stage. We collected data using a questionnaire that was translated into the local language for those unable to speak English.

\section{Inclusion and exclusion criteria}

The boda boda cyclists were eligible to participate if they were residing within Mbarara municipality, had been riding for at least 6 months, a period required for them to obtain an official registration from the Municipal commercial officers. Participants were enrolled if they provided individual informed consent to participate in 
the study. We enrolled participants of 18 to 59 years of age. We did not enroll those who operate on night duty as they were not available for interview during normal working hours.

\section{Measurements}

We designed a tool (attached as supplementary material) and collected data on social demographics and income. We also collected data on sports-betting, and asked if they had ever been involved in sports-betting, and the frequency of their involvement. The participants in our study do not have access to other forms of gambling other than sports-betting, and therefore sports-betting and gambling are used interchangeably in our description. We collected data on alcohol consumption and used the Alcohol Use Disorders Identification Test (AUDIT) tool, a 10-item screening tool developed by the World Health Organization [20]. We asked participants about their smoking habits, namely whether they had ever smoked and if they had smoked in the past 6 months.

\section{Data analysis}

We summarized numeric data using descriptive statistics namely means and standard deviations or medians with interquartile ranges (IQR), and categorical data using frequencies and percentages. We coded sports-betting as a dichotomous outcome. We considered a rider to have engaged in sports-betting if they reported they had been actively involved in sports-betting in the past 30 days. We defined active sports-betting as spending money to complete a transaction in a sports-betting activity. We coded the outcome as " 1 " when the participant was involved in sports-betting or " 0 " when not involved. Alcohol consumption was classified into three categories based on the AUDIT-C score namely low, moderate and high based on the volume of consumption with the smallest consumers in the low category and the largest consumers in the high category. An AUDIT score of 0 to 4 was considered low, 5 to 8 was classified as moderate and any score higher than 8 was considered high or hazardous alcohol use.

We examined categorical variables such as marital status, residence and alcohol consumption by sportsbetting status using the Chi-square test, when the cell count was large $(\geq 5)$ or the Fisher's exact test when cell count was small $(<5)$. We examined continuous variables such as age by sports-betting status, and here we used the student's t-test when the data were normally distributed or the Wilcoxon sum rank test when skewed. We tested our hypothesis using a two sided test approach and 0.05 as the level of significance.

The proportion of the outcome variable was considered highly frequent, so the odds ratio (OR) is not an appropriate measure of effect because it would overestimate the strength of the association [21, 22]. Therefore, for the regression analysis, we computed risk ratios (RR) using modified Poisson regression with robust error variance to control for potential violations of the assumptions of Poisson regression analysis. The primary exposure for this analysis was alcohol consumption and the outcome was sports-betting. In the regression analysis, we calculated unadjusted RR ( $u R R$ ) and their 95\% confidence intervals (CI). We then fitted a multivariable model for variables that showed $p$ values less than 0.1 at the unadjusted analysis and then reported the adjusted RR (aRR) and 95\% CI. Prior to the multivariate analysis, we checked for multicollinearity and considered variance inflation factor (VIF) greater than 10 as indicator of collinearity. We also checked model fitness using Akaike Information Criteria (AIC), link test, and goodness of fit (GOF) test. We considered the AIC (389.4) from our model as low and a statistically non-significant $p$-value for the link test $(p=0.850)$ and the GOF test (Pearson GOF $=317.2$, chi-square $=386, p=0.996)$ as indicative of good model fit. Furthermore, we checked for the assumption of normal distribution by plotting a graph of residuals of the fitted versus residual values.

\section{Human subjects}

The study was approved by the Research Ethics Committee at Mbarara University of Science and Technology. Study procedures were adherent to the requirements under the Helsinki declaration. Participants were invited and voluntarily accepted to participate. Individual informed and written consent was obtained from all participants, and all were at least 18 years of age. Consent process was conducted in the local language to enhance understanding. In the reporting of results, divisions of residence have been left anonymous to protect group confidentiality.

\section{Results}

Socio-demographic characteristics of participants

We approached 425 eligible riders and enrolled 401 of them. Twenty four (5.6\%) participants of those approached declined to participate. The mean age (standard deviation) of those enrolled participants was $29.3 \pm 5.9$ years (median age, 29.0; Interquartile range or IQR, 25-32). Table 1 presents a summary of the sociodemographic characteristics of participants stratified by sports-betting status. There was no statistically significant difference in mean age between participants who engaged in sports-betting and those who never: $28.9 \pm$ 5.4 versus $29.4 \pm 6.1$, respectively; $p=0.56$. Statistically significant differences by sports-betting were observed with respect to time for end of work day $(p=0.043)$, alcohol consumption $(p=0.002)$ and smoking status. Riders who end their work day before 7:00 pm are more 
Table 1 Characteristics of motorcycle taxi riders by sports betting status, Mbarara municipality, Uganda

\begin{tabular}{|c|c|c|c|c|}
\hline \multirow{2}{*}{ Characteristics } & \multirow[b]{2}{*}{ Level } & \multicolumn{2}{|c|}{ Engaged in sports betting } & \multirow[b]{2}{*}{$p$ value } \\
\hline & & No $(n=327)$ & Yes $(n=74)$ & \\
\hline \multirow[t]{4}{*}{ Division of residence } & A & 110 (33.6) & $23(31.1)$ & 0.185 \\
\hline & B & $79(24.2)$ & $24(32.4)$ & \\
\hline & C & $108(33.0)$ & $17(23.0)$ & \\
\hline & $\mathrm{D}$ & $30(9.2)$ & $10(13.5)$ & \\
\hline Mean age (SD) & & $29.42(6.07)$ & $28.97(5.41)$ & 0.558 \\
\hline \multirow[t]{4}{*}{ Religion } & Catholic & $123(37.6)$ & $25(33.8)$ & 0.131 \\
\hline & Protestant & $138(42.2)$ & $38(51.4)$ & \\
\hline & Moslem & $45(13.8)$ & $4(5.4)$ & \\
\hline & Others & $21(6.4)$ & $7(9.5)$ & \\
\hline \multirow[t]{2}{*}{ Educational level } & None/primary & $204(62.6)$ & $44(59.5)$ & 0.618 \\
\hline & Secondary/Tertiary & $122(37.4)$ & $30(40.5)$ & \\
\hline \multirow[t]{3}{*}{ Marital status } & Never married & $90(27.5)$ & $18(24.3)$ & 0.428 \\
\hline & Married & $218(66.7)$ & $54(73.0)$ & \\
\hline & Separated & $19(5.8)$ & $2(2.7)$ & \\
\hline \multirow[t]{3}{*}{ Number of children } & $\leq 2$ & $211(64.9)$ & $49(66.2)$ & 0.977 \\
\hline & $3-5$ & $100(30.8)$ & $22(29.7)$ & \\
\hline & $>5$ & $14(4.3)$ & $3(4.1)$ & \\
\hline \multirow[t]{2}{*}{ Owns a boda boda } & No & $169(51.8)$ & $40(55.6)$ & 0.659 \\
\hline & Yes & $157(48.2)$ & $32(44.4)$ & \\
\hline \multirow[t]{2}{*}{ Income per day in dollars } & $<5$ & $135(41.7)$ & $40(54.1)$ & 0.071 \\
\hline & $\geq 5$ & $189(58.3)$ & $34(45.9)$ & \\
\hline \multirow[t]{2}{*}{ End of work day } & Before $7.00 \mathrm{pm}$ & $38(11.8)$ & $16(21.6)$ & $0.043^{*}$ \\
\hline & After 7.00 pm & $283(88.2)$ & $58(78.4)$ & \\
\hline \multirow[t]{3}{*}{ Alcohol consumption } & Low & $266(81.3)$ & $49(66.2)$ & $0.002^{* *}$ \\
\hline & Moderate & $40(12.2)$ & $21(28.4)$ & \\
\hline & High & $21(6.4)$ & $4(5.4)$ & \\
\hline \multirow[t]{2}{*}{ Ever smoked cigarettes } & No & $296(90.5)$ & $52(70.3)$ & $<0.001^{* * *}$ \\
\hline & Yes & $31(9.5)$ & $22(29.7)$ & \\
\hline \multirow[t]{2}{*}{ Smoked cigarettes in the past 6 months } & No & $301(92.0)$ & $58(78.4)$ & $0.001^{* * *}$ \\
\hline & Yes & $26(8.0)$ & $16(21.6)$ & \\
\hline \multirow[t]{2}{*}{ Ever smoked marijuana } & No & $305(93.3)$ & $66(89.2)$ & 0.337 \\
\hline & Yes & $22(6.7)$ & $8(10.8)$ & \\
\hline \multirow[t]{2}{*}{ Ever smoked marijuana in the past 6 months } & No & $320(98.8)$ & $71(95.9)$ & 0.24 \\
\hline & Yes & $4(1.2)$ & $3(4.1)$ & \\
\hline
\end{tabular}

Note: 1$)^{*} p<0.05,{ }^{* *} p<0.01,{ }^{* * *} p<0.001$ at $5 \%$ level of significance

likely to engage in sports-betting compared to those who end their work day after 7:00 pm. Alcohol consumption and smoking are more frequent among persons who were engaged in sports-betting compared to those who were not. The other variables such as the division of residence, religion, educational level, marital status, number of children, income per day and ownership of a motorcycle taxi did not differ (all $p>0.05$ ) between participants who engaged in sports-betting and those that did not. Although the riders who smoke cigarettes were more likely to engage in sports-betting, use of marijuana was not related to sports-betting.

\section{Frequency and pattern of sports-betting}

The results for frequency and pattern of sports-betting are presented in Table 2 below. Of the 401 participants, 74 (18.5\%) had engaged in sports-betting in the past 30 days. Among those that reported sports-betting in the 
Table 2 Frequency and pattern of sports-betting among motorcycle taxi riders in Mbarara municipality, Uganda

\begin{tabular}{lll}
\hline Characteristics & Category & $\mathbf{n}(\%)$ \\
\hline Ever engaged in sports-betting in the past 30 days $(n=401)$ & No & $327(81.5)$ \\
& Yes & $74(18.5)$ \\
Pattern of sports-betting in the past 30 days $(n=74)$ & Daily or Almost daily & 16(21.6) \\
& Weekly $(36.5)$ & $31(41.9)$ \\
\hline
\end{tabular}

past 30 days, 31 or $41.9 \%$ engaged less than weekly, 27 (36.5\%) engaged weekly while $16(21.6 \%)$ daily or almost daily.

\section{Factors associated with sports-betting}

We present the results of the regression analysis in Table 3. In the unadjusted analysis, data show that earning five or more dollars per day was not significantly associated with betting (Unadjusted risk ratio or uRR, 0.67; 95\% CI, 0.44-1.01), although marginally significant. Riders who end work day after 7.00 pm (uRR, 0.55; 95\% CI, 0.36-0.93) were less likely to engage in sportsbetting. Alcohol consumption was significantly associated with sports-betting. There was a more than 2 fold increase in the likelihood of sports-betting among those in the moderate alcohol consumption category (uRR, 2.21 ; $95 \%$ CI, 1.44-3.41) with the low consumption category as the referent. The association was not significant among those in the high consumption category (uRR, 1.03; 95\% CI, 0.40-2.62). Smoking was significantly associated with sports-betting uRR 2.36, 95\% 1.50, 3.71).

After adjusting for potential confounders, riders who end the work day after $7.00 \mathrm{pm}$ were $38 \%$ (adjusted risk ratio or aRR, 0.62 ; 95\% CI, 0.39-0.99) less likely to engage in sports-betting compared to those who end the day before $7.00 \mathrm{pm}$. We observed an inverted U relationship between alcohol consumption and sports-betting. Riders in the moderate alcohol consumption category were nearly 2 times more likely to engage in sportsbetting compared to those in the low consumption category (aRR,1.86; 95\% CI, 1.18-2.94). However, among those in the high consumption category, the relationship was not significant. Smoking remained significantly associated with sports-betting after adjustment for all other variables in the model with aRR 1.85 (95\% CI 1.13, 3.01). Income earned per day was not significantly related to sports-betting but those who ended their work day after $7 \mathrm{pm}$ were less likely to engage in sports-betting compared to those who end their work day earlier.

\section{Discussion}

Our data show that $18.5 \%$ of the motorcycle taxi riders have been involved in sports-betting in the most recent month, and that among those that engage in sportsbetting, about one fifth of them engage daily or nearly daily. Our data show that riders who stop work earlier are more likely to engage in gambling, but most importantly, alcohol consumption and cigarette smoking were significantly associated with gambling. Income earned per day is unrelated to the likelihood to get engaged in sports-betting. Our study is one of the few from sub Saharan Africa that have examined the association between alcohol consumption and gambling.

The frequency of sports-betting in our study population is comparable to that from a study in the United States [23], although this was an American student

Table 3 Modified poisson regression analysis of the relationship between alcohol and sports-betting among motorcycle taxi riders, Mbarara municipality, Uganda

\begin{tabular}{|c|c|c|c|c|c|}
\hline \multirow[b]{2}{*}{ Characteristics } & \multirow[b]{2}{*}{ Level } & \multicolumn{4}{|c|}{ Modified Poisson regression analysis } \\
\hline & & uRR & $95 \% \mathrm{Cl}$ & aRR & $95 \% \mathrm{Cl}$ \\
\hline \multirow[t]{2}{*}{ Income per day/dollars } & $<5$ & 1 & & 1 & \\
\hline & $\geq 5$ & 0.67 & $(0.44,1.01)$ & 0.74 & $(0.49,1.11)$ \\
\hline \multirow[t]{2}{*}{ End of work day } & Before $7.00 \mathrm{pm}$ & 1 & & 1 & \\
\hline & After 7.00 pm & $0.57^{*}$ & $(0.36,0.92)$ & $0.62^{*}$ & $(0.39,0.99)$ \\
\hline \multirow[t]{2}{*}{ Smoked cigarettes in last 6 months } & No & 1 & & 1 & \\
\hline & Yes & $2.36^{* * *}$ & $(1.50,3.71)$ & $1.85^{*}$ & $(1.13,3.01)$ \\
\hline \multirow[t]{3}{*}{ Alcohol consumption } & Low & 1 & & 1 & \\
\hline & Moderate & $2.21^{* * *}$ & $(1.44,3.41)$ & $1.86^{* *}$ & $(1.18,2.94)$ \\
\hline & High & 1.03 & $(0.40,2.62)$ & 0.97 & $(0.37,2.58)$ \\
\hline
\end{tabular}

Note: 1$)^{*} p<0.05,{ }^{* *} p<0.01,{ }^{* * *} p<0.001$ at $5 \%$ level of significance; 2 ) 95\% confidence intervals for risk ratio (RR) in brackets; 3) aRR: Adjusted Risk Ratio; 4) uRR: Unadjusted Risk Ratio; 5) Risk Ratios are exponentiated coefficients 
population. However, the frequency in our study population is only half of that demonstrated in a South Africa population [24]. This study in South Africa was conducted among a general adult population, mostly low income poor population. Our study population consists of low income earners as well but younger. However, the frequency gambling in South Africa is much higher and may be because gambling is well established there and has been practiced since the 1990s and with a variety of options unlike in Uganda. A Ugandan study showed that about one in every four adults in the capital Kampala, had engaged in some form of gambling in the past 12 months [6], which is comparable to the frequency of gambling in our study. Studies elsewhere in sub Saharan Africa show gambling is prevalent in both rural and urban settings mostly among the youth as pass time and some have sold household goods to finance their gambling activities [25]. In our study population, sportsbetting was the only form of gambling available to the riders. Other forms of gambling such as casinos are available in the capital Kampala, but are likely to be accessed by the higher income earners as the costs of gambling in the casinos are likely to be higher.

Our findings of the association between alcohol consumption and gambling are in agreement with those of a study in South Africa among a population of gamblers [26]. Our findings are also consistent with those of a study conducted among residents of Kampala city, Uganda [5]. The results confirm our primary hypothesis and agree with several other studies outside the African continent such as those studies conducted in the United States [27, 28], United Kingdom [29], and Sweden [30]. We observed an inverted $U$ association, an indication that among the heavy drinkers, there was no association with sports-betting. It is not clear whether alcohol consumption precedes gambling or vice-versa, in the pathway and whether there is a causal relationship and what the mechanism may be. Studies suggest alcohol drinking may increase the propensity to gamble [31]. There is possibility that heavy drinkers lose their income to drinking and have limited resources left to gamble, explaining the inverted $U$ shape relationship.

Our study also shows a significant association between cigarette smoking and sports-betting. This finding fits our hypothesis and also agrees with findings from other studies [32]. Alcohol and nicotine in the cigarettes are both substances of addiction and their close association with gambling, which is also addictive is not unexpected. Our data adds to the limited existing evidence of the link between the use of alcohol and cigarettes with gambling in sub Saharan Africa [26]. For the continent, these results are significant because of the close association of all these exposures with mental health conditions, which are much neglected area on the continent. Alcohol, substance abuse, anxiety and depression are highly prevalent among persons with problem gambling [33]. Marijuana was not commonly used and our data did not have sufficient numbers to explore its association with sports-betting.

The finding that participants who ended work after $7.00 \mathrm{pm}$ are less likely to engage in sports betting is novel but not surprising. We hypothesized that the riders who leave work before $7.00 \mathrm{pm}$ have more time to watch football matches on television, which are usually played in the late evening hours and to participate in sports betting. The riders who end work after $7.00 \mathrm{pm}$ would have less opportunity to follow live games and place their bets.

It is important to note that we conducted our study among motor cycle taxi riders, a sub-group of the population that comprises predominantly young male Ugandans. We chose this group because they represent a large proportion of urban male youth who earn a living from a meager daily income. Youth unemployment is very high in Uganda with more than $60 \%$ of youth aged between 18 and 35 years facing unemployment. Motorcycle taxis provide an option for them to earn a living. These results are therefore generalizable to a large proportion of out of school male youth and young adults in Uganda.

\section{Study strengths and limitations}

Although our study provides unique data from sub Saharan Africa, it has some weaknesses. We did not measure the severity of the gambling. There are well established tools to do this such as the Gambling severity index score. Future studies should consider including the measurement of the grade of severity of gambling and the social and economic consequences of gambling. Our sample size was relatively small and may limit the external validity of our findings. In addition, we had a $5.6 \%$ non-response, and although this is small, we did not compare the features of these non-responders to those who were enrolled and there might have been a bias introduced. Third, we did not collect data on amounts of money spent on alcohol consumption, smoking, and sports-betting, and to establish the impact of expenditures on these items on each other. These gaps should be the focus for further research. Furthermore, qualitative data are needed to gain in-depth understanding on the reasons or facilitators of sports betting and the subsequent consequences.

The strength of our study is that it presents data on gambling, a practice that is growing in sub Saharan Africa, yet under researched on the continent. The finding of an inverted $U$ relationship between alcohol consumption and sports-betting is novel and should be further examined and replicated in other studies. Although several studies have shown the association between 
substance abuse and gambling [23, 34, 35], very few such studies have been done in resource limited settings.

\section{Conclusions}

In conclusion, our study has shown that gambling via sports-betting occurs in almost two in every 10 boda boda motorcyclists, a low income category group of predominantly male youth and young adults in Uganda. Our study shows that sports-betting is associated with alcohol consumption and cigarette smoking and is also more likely to occur among riders who end the work day earlier. Although our data do not provide evidence on the long term outcomes of sports betting, there is concern that sports-betting is on the rise and some of the participants bet daily or nearly daily and may be at risk for developing problem gambling and addiction. We recommend that future studies should examine this relationship.

Our findings have important implications. There is a need to put in place policies and structures to regulate the use of sports-betting services. The regulation will likely face significant challenges because sports-betting services can be accessed easily via mobile phones by users in the privacy of their homes. In addition, sports-betting is legal in Uganda and many other countries in sub Saharan Africa and the industry is lucrative and contributes revenue to the government coffers through taxation. There is a likelihood that interventions to regulate access to sportsbetting may be met with resistance from certain stakeholders that benefit from the business. We recommend that future research should explore gambling expenditure. Also, research on policy should be done to address the current regulatory frameworks, industry influence on government and regulation, advertising and marketing to fully contextualize any proposed interventions. Lastly, given the close association between sports-betting and alcohol consumption, interventions should be co-packaged to deal with the two public health challenges concurrently.

\section{Supplementary Information}

The online version contains supplementary material available at https://doi. org/10.1186/s12889-021-10406-7

Additional file 1. Supplementary material-study tool (Study tool).

\section{Abbreviations}

AUDIT: Alcohol Use Disorders Identification Test; aRR: Adjusted relative risk; GOF: Goodness of fit; uRR: Unadjusted relative risk

\section{Acknowledgements}

We thank the staff and faculty at the Department of Community Health for the material and moral support provided in the data collection.

\section{Authors' contributions}

FB conceived the idea. SCN and FB supervised the data collection, SCN and $\mathrm{Jl}$ did the data entry, analysis and drafted the tables. FB did the first draft of the manuscript. All authors approved the final version of the manuscript.

\section{Funding}

This work is part of a Masters of Public Health dissertation for SCN. The work was supported by the First Mile Program at the Department of Community Health.

Availability of data and materials

Data are available upon reasonable request from corresponding author (fbaj@yahoo.com) and with approval from the Research Ethics committee. Please email sec.rec@must.ac.ug

\section{Ethics approval and consent to participate}

The study was approved by the Research Ethics Committee at Mbarara University of Science and Technology. Study procedures were adherent to the requirements under the Helsinki declaration. Participants were invited and voluntarily accepted to participate. Individual informed and written consent was obtained from all participants, who were all adults above 18 years. Consent process was conducted in the local language to enhance understanding.

\section{Consent for publication}

Not applicable as no personal information in included in the results.

\section{Competing interests}

The authors declare that there are no competing interests.

Received: 11 August 2020 Accepted: 7 February 2021

Published online: 16 February 2021

\section{References}

1. Bunn C, Ireland R, Minton J, Holman D, Philpott M, Chambers S. Shirt sponsorship by gambling companies in the English and Scottish premier leagues: global reach and public health concerns. Soccer Soc. 2019;20(6): 824-35.

2. Foley-Train J. Sports betting: Commercial and integrity issues. Report prepared for the Association of British Bookmakers, European Gaming and Betting Association, European Sport Security Association and Remote Gambling Association Retrieved January 2014, 21; 2015.

3. Lopez-Gonzalez H, Griffiths MD. Betting, Forex trading, and fantasy gaming sponsorships-a responsible marketing inquiry into the 'Gamblification' of English football. Int J Ment Heal Addict. 2018;16(2):404-19.

4. Herskowitz S. Gambling, saving, and lumpy expenditures: sports betting in Uganda. Berkeley: University of California; 2016.

5. Ahaibwe G, Lakuma PC, Katunze M, Mawejje J. Socio-economic effects of gambling: evidence from Kampala City, Uganda. Kampala: Economic Policy Research Center; 2016. p. 2-17.

6. The New Vision Uganda newspaper. 2020. https:/www.bukedde.co.ug/ ebyemizannyo/1532135/note-about-rise-sports-betting-uganda.

7. Ayandele O, Popoola O, Obosi AC. Influence of demographic and psychological factors on attitudes toward sport betting among young adults in Southwest Nigeria. J Gambl Stud. 2020;36(1):343-54.

8. Yawe BL, Ssengooba K. Gambling and Mobile money payments: a case study of sports betting in Uganda. Retrieved on October 2014; 2018. p. 18

9. Binde P. Gambling advertising: a critical research review. In: Responsible Gambling Trust; 2014.

10. Hanss D, Mentzoni RA, Griffiths MD, Pallesen S. The impact of gambling advertising: problem gamblers report stronger impacts on involvement, knowledge, and awareness than recreational gamblers. Psychol Addictive Behav. 2015;29(2):483-91.

11. Binde $\mathrm{P}$, Romild U. Self-reported negative influence of gambling advertising in a Swedish population-based sample. J Gambl Stud. 2019;35(2):709-24.

12. Kalischuk RG, Nowatzki N, Cardwell K, Klein K, Solowoniuk J. Problem gambling and its impact on families: a literature review. Int Gambl Stud. 2006;6(1):31-60

13. Sharman S, Ferreira CA, Newall PWS. Exposure to gambling and alcohol marketing in soccer matchday programmes. J Gambl Stud. 2020;36(3):97988. https://doi.org/10.1007/s10899-019-09912-6.

14. Lopez-Gonzalez H, Estévez A, Jiménez-Murcia S, Griffiths MD. Alcohol drinking and low nutritional value food eating behavior of sports bettors in gambling advertisements. Int J Ment Heal Addict. 2018;16(1):81-9. 
15. Blankenship J, Starling R, Woodall WG, May PA. Gambling and alcohol use: trends in the state of New Mexico from 1996-1998. J Gambl Stud. 2007; 23(2):157-74.

16. French MT, Maclean JC, Ettner SL. Drinkers and bettors: investigating the complementarity of alcohol consumption and problem gambling. Drug Alcohol Depend. 2008;96(1-2):155-64.

17. Weinberger AH, Franco CA, Hoff RA, Pilver C, Steinberg MA, Rugle L, Wampler J, Cavallo DA, Krishnan-Sarin S, Potenza MN. Cigarette smoking, problem-gambling severity, and health behaviors in high-school students. Addict Behav Rep. 2015;1:40-8.

18. Böckerman P, Hyytinen A, Kaprio J, Maczulskij T. If you drink, don't smoke: joint associations between risky health behaviors and labor market outcomes. Soc Sci Med. 2018;207:55-63.

19. Galukande M, Jombe J, Faulal J, Gakwaya J. Boda-Boda injuries a health problem and burden of disease in Uganda: a tertiary hospital survey. East Cent Afr J Surg. 1990;14(2):33-7.

20. Babor TF, de la Fuente JR, Saunders J, Grant M. The alcohol use disorders identification test: guidelines for use in. Primary care; 2001.

21. Schmidt OC, Kohlmann T. When to use the odds ratio or the relative risk? Int J Public Health. 2008:53:165-7.

22. Spiegelman D, Hertzmark E. Easy SAS calculations for risk or prevalence ratios and differences. Am J Epidemiol. 2005:162(3):199-200.

23. Zhai ZW, Duenas GL, Wampler J, Potenza MN. Gambling, substance use and violence in male and female adolescents. J Gambl Stud. 2020;36(4):1301-24. https://doi.org/10.1007/s10899-020-09931-8.

24. Dellis A, Spurrett D, Hofmeyr A, Sharp C, Ross D. Gambling participation and problem gambling severity among rural and peri-urban poor south African adults in KwaZulu-Natal. J Gambl Stud. 2013;29(3):417-33.

25. Amutabi MN. Gambling addiction and threat to development in Kenya: assessing the risks and problems of gamblers in changing society; 2018 .

26. Skaal L, Sinclair H, Stein DJ, Myers B. Problem gambling among urban and rural gamblers in Limpopo Province, South Africa: associations with hazardous and harmful alcohol use and psychological distress. J Gambl Stud. 2016;32(1):217-30.

27. Walker DM, Clark C, Folk J. The relationship between gambling behavior and binge drinking, hard drug use, and paying for sex. UNLV Gaming Res Rev J. 2010:14(1):15-26.

28. Thorne HB, Browne M, Rockloff MJ, Ferguson SA. That's what you get for waking up in Vegas: fatigue and alcohol consumption are associated with the duration of gambling sessions. J Gambling Issues. 2019;42:146-62.

29. Bohane G, Guerrier Y, Sakhuja R, Vamvakari T. The Relationship Between Alcohol and Gambling Behaviours. London: University of Roehampton Business School; 2015. p. 1-3.

30. Håkansson A. Changes in gambling behavior during the COVID-19 pandemic - a web survey study in Sweden. Int J Env Res Public Health. 2020;17(4013):1-16.

31. Barrett SP, Collins P, Stewart SH. The acute effects of tobacco smoking and alcohol consumption on video-lottery terminal gambling. Pharmacol Biochem Behav. 2015;130:34-9.

32. Hammond CJ, Pilver CE, Rugle L, Steinberg MA, Mayes LC, Malison RT, Krishnan-Sarin S, Hoff RA, Potenza MN. An exploratory examination of marijuana use, problem-gambling severity, and health correlates among adolescents. J Behav Addict. 2014;3(2):90-101.

33. Sharp C, Dellis A, Hofmeyr A, Kincaid H, Ross D. First evidence of comorbidity of problem gambling and other psychiatric problems in a representative urban sample of South Africa. J Gambl Stud. 2015;31(3):679-94.

34. Ethier AR, Kim HS, Hodgins DC, McGrath DS. High rollers: correlates of problematic cocaine use among a community sample of gamblers. J Gambl Stud. 2020:36(2):513-25. https://doi.org/10.1007/s10899-020-09943-4.

35. Dufour M, Nguyen N, Bertrand K, Perreault M, Jutras-Aswad D, Morvannou A, Bruneau J, Berbiche D, Roy É. Gambling problems among community cocaine users. J Gambl Stud. 2016;32(3):1039-53.

\section{Publisher's Note}

Springer Nature remains neutral with regard to jurisdictional claims in published maps and institutional affiliations.

\section{Ready to submit your research? Choose BMC and benefit from:}

- fast, convenient online submission

- thorough peer review by experienced researchers in your field

- rapid publication on acceptance

- support for research data, including large and complex data types

- gold Open Access which fosters wider collaboration and increased citations

- maximum visibility for your research: over $100 \mathrm{M}$ website views per year

At BMC, research is always in progress.

Learn more biomedcentral.com/submissions 